\title{
Inventaire et incidence des insectes inféodes à la culture du fonio (Digitaria exilis Stapf) dans la zone ouest du Burkina Faso
}

\author{
Issoufou OUEDRAOGO ${ }^{1}$; Omer S. Hema ${ }^{1}$ et Adama SANOU 1 \\ 1 INERA/Station de Farako-Bâ, 01 BP 910 Bobo- Dioulasso 01- Burkina Faso. \\ Corresponding author's e-mail : yeguere@yahoo.com
}

Original submitted in on $26^{\text {th }}$ August 2015. Published online at www.m.elewa.org on $31^{\text {st }}$ October 2015

http://dx.doi.org/10.4314/jab.v94i1.11

\section{RÉSUMÉ}

Objectif : Identifier les principales contraintes à la production fonio dans la zone ouest du Burkina Faso en particulier les insectes et les mauvaises herbes rencontrés sur cette culture durant la phase végétative dans la zone ouest du Burkina Faso.

Méthodologie et résultats : L'identification des contraintes associées à la production du fonio au champ a été faite à travers la capture des insectes et l'identification des mauvaises herbes qui colonisent cette culture. Les captures des insectes ont été réalisées à travers les piégeages à l'aide des bacs jaunes et du filet fauchoir. L'évaluation des mauvaises herbes qui infestent la culture du fonio a été faite durant leur période d'inflorescences. Les résultats ont montré que le fonio est colonisé par plusieurs ordres d'insectes dont les plus importants sont constitués par les Homoptères, les Coléoptères, les Orthoptères et les Lépidoptères. Au total 38 familles d'espèces d'insectes ont été capturés sur le fonio. Parmi ces insectes, plusieurs espèces de cicadelles appartenant au genre Cicadulina ont été retrouvées sur le fonio, il en est de même des Spodoptères qui relèvent de l'ordre des lépidoptères. Quant aux mauvaises herbes, 17 espèces ont été recensées sur cette culture. L'importance des insectes capturés sur le fonio est liée à la multitude des adventices qui infestent le fonio et qui favorisent le développement des insectes nuisibles.

Conclusion et application : La culture de fonio est infestée par un nombre important d'insectes appartenant essentiellement à l'ordre des homoptères, des coléoptères et des lépidoptères. Les plants de fonio constituent pour ces insectes non seulement une source alimentaire et un support de ponte mais également un refuge. Cette relation entre les insectes et le fonio permet une prolifération des cicadelles du genre Cicadulina, vecteurs du virus de la striure du maïs avant qu'ils s'attaquent aux plantes sur lesquelles les dégâts sont plus importants. Plusieurs mauvaises herbes infestent le fonio et la diversité spécifique de ces adventices de même que la diversité des insectes capturés sur le fonio est à la base d'une baisse de la qualité et de la quantité de fonio produite surtout lorsque cette production concerne les semences. La connaissance des facteurs qui déprécient la qualité du fonio permet une gestion efficiente de ces facteurs afin de produire un fonio de qualité destiné pour la consommation humaine que comme des semences.

Mots clés : Digitaria exilis, Fonio, Entomofaune, Burkina Faso, Insectes- Adventices 


\section{Ouedraogo et al. J. Appl. Biosci. 2015 Inventaire et incidence des insectes inféodes à la culture du fonio (Digitaria exilis Stapf) dans la zone ouest du Burkina Faso.}

\section{Inventory and impact of insects on Digitaria exilis stapf (Fonio) in the west of Burkina Faso ABSTRACT}

Objective: Identify the main constraints to Digitaria exilis) (Fonio) production in the western area of Burkina Faso, in particular insects and weeds encountered on this culture during the vegetative phase.

Methodology and results: identification of the constraints associated to the production of Digitaria axilis in the field was done through the capture of insects and the identification of weeds, which colonize this culture. Insect were caught through traps using the yellow bins and the sweep nets. Weeds that infest Digitaria axilis cultivation were evaluated during their flowering. The results showed that Digitaria axilis is colonized by several orders of insects and the most important are Homoptera, Coleoptera, Orthoptera and Lepidoptera. Thirty eight (38) families of insect species were captured on Digitaria axilis. Among these insects, several species of Cicadulina gender were found, as well as Spodoptera belonging to Lepidopteran order. As far as weeds are concerned, 17 species were recorded on this plant. The importance of insects captured on Digitaria axilis is linked to the multitude of weeds that infest this plant and which promote the development of insect pests.

Conclusion and application: Digitaria exilis is infested by a large number of insect species, mainly belonging to Homoptera, Coleoptera and Lepidoptera orders. Digitaria exilis is for these insects not only a feeding source and an egg laying area but also a refuge. This relationship between insects and Digitaria exilis allows a proliferation of Cicadulina gender, vector of the maize streak virus until they attack the plants on which the damage is most important. Several weed species infest Digitaria exilis and their diversity as well as the diversity of insect species captured on this culture is in the basis of a reduction of the quality and the quantity of its production, especially when it is about seeds production.

Key words: Digitaria exilis, entomofauna, Burkina Faso, insects, weeds.

\section{INTRODUCTION}

Le fonio (Digitaria exilis Stapf) (Photo 1) est une céréale traditionnelle endémique de l'Afrique de l'Ouest (Portères, 1955), elle est cultivée dans plusieurs pays qui s'étendent du Sénégal au Lac Tchad (KonkoboYameogo et al.2004) et les superficies emblavées sont estimée à 360000 hectares en 2008 (FAO STAT, 2010). En Afrique subsaharienne de l'ouest, le fonio constitue à la fois une culture de rente et une culture vivrière. Dans cette zone, Cette culture connaît actuellement un regain d'intérêt en zone urbaine du fait de ses vertus diététiques et thérapeutiques (KonkoboYameogo et al. 2004). En zone rurale, le fonio apparaît comme une culture de soudure entrant dans une stratégie de lutte contre l'insécurité alimentaire saisonnière en Afrique de l'Ouest (Vall et al, 2011).Au Burkina Faso, le fonio est cultivé dans la partie ouest et nord-ouest du pays (Cruz et al, 2005) et il occupe la $5^{\text {eme }}$ place parmi les céréales cultivées au Burkina Faso qui sont largement dominée par le mil, le sorgho et le maïs (Cruz, 2000). Les superficies emblavées en fonio ont atteint34 000 hectares en 2011 (MAHRH/DPSAA, 2011) contre 24000 hectares en 2008 (Val et al, 2008). Malgré l'intérêt que cette culture connaît, la production $\mathrm{du}$ fonio reste faible avec un rendement moyen de $721 \mathrm{~kg} / \mathrm{ha}$, cette situation est le résultat de plusieurs facteurs parmi lesquels on peut citer la non maîtrise des itinéraires techniques, l'absence de fertilisation adéquate mais également la prolifération des mauvaise herbes et les attaques dinsectes favorisant la baisse de la productivité de cette céréale. En effet, les travaux sur l'impact des insectes sur le fonio sont très peu nombreux à l'exception de ceux d'Umaru et al (2010) au Nigeria. Le fonio est une céréale dont la production connaît une croissance durant ces dernières années, et pour soutenir cette production, beaucoup de travaux de recherche ont été initiés sur le fonio mais essentiellement orientés vers les technologies post récolte (Cruz et al. 2000). Les recherches menées sur les techniques culturales et la fertilisation du fonio sont rares et anciennes (Gigou et al, 2009). Cependant, un accroissement de la production de cette céréale passe par une connaissance des facteurs biotiques qui peuvent influencer l'évolution de la plante durant sa phase végétative. C'est dans ce cadre que s'inscrivent nos travaux qui portent sur l'inventaire des populations d'insectes inféodés à la culture du fonio dans la zone ouest du Burkina Faso. L'identification précise des insectes inféodés au fonio permettra l'élaboration d'une stratégie de lutte basée sur l'éthologie de ces insectes nuisibles. L'absence d'information sur les insectes qui infestent le fonio peut influencer la qualité et la quantité de production de cette céréale dans les zones de production. 


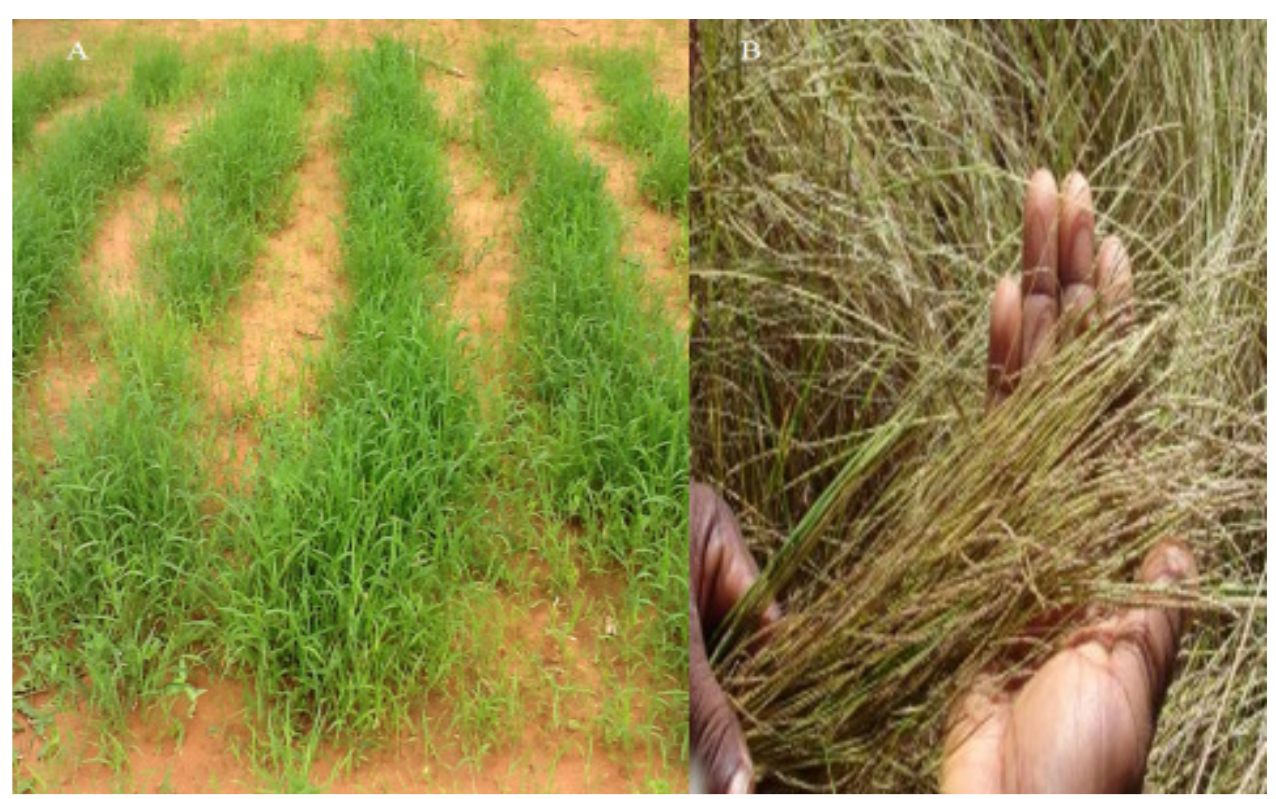

Photo 1 : A : Variété de Fonio CVF 109 semée en lignes continues, B : Panicules de Fonio à la récolte

\section{MATERIEL ET METHODES}

Zone d'étude: Les travaux ont été conduits à la station de recherches agricoles de Farako-Bâ à BoboDioulasso dans la zone ouest du Burkina Faso. Elle présente les coordonnées suivantes : une longitude de $4^{\circ} 20^{\prime}$ Ouest, une latitude de $11^{\circ} 06^{\prime}$ Nord et une altitude de 405 mètres. Les expérimentations se sont déroulées durant les campagnes agricoles 2013 et 2014.

Matériel végétal : Le matériel végétal utilisé est une semence de fonio de la variété CVF109. C'est une des variétés les plus performantes de la collection avec un rendement moyen compris entre 1500 et $2000 \mathrm{~kg}$ à l'hectare. C'est une variété à port rampant ayant un cycle de 95 jours.

Matériel techniques: Le matériel techniques utilisés durant nos travaux sont constitués de :

1) un filet fauchoir : II est composé d'un manche plus ou moins long auquel est rattaché un cercle métallique fixe et rigide rattaché à un filet à maille fine. II est destiné à la capture d'insectes présents sur le tapis herbacé ;

2) Les bacs jaunes: Ce sont des bacs en plastiques de couleur jaune bouton d'or de diamètre $20 \mathrm{~mm}$. Dans ces bacs contenant de l'eau, on a ajouté quelques gouttes de savon liquide. Les bacs sont ensuite placés dans les parcelles pour la capture des insectes.

3) Une loupe binoculaire de marque Vision SX 45 a été utilisé pour le tri, le comptage et l'identification des insectes.

Méthodes de capture des insectes
Dispositif expérimental utilisé : Le dispositif expérimental utilisé est un bloc Fisher qui comprend quatre répétitions et quatre traitements qui sont :

T0: Parcelles témoins qui ne reçoivent aucun traitement ;

T1 : Parcelles dont les semences ont été traitées avec un insecticide (Chlorpyriphos éthyle $25 \%$ + Thirame $25 \%)$;

T2: Parcelles dont les semences ont été traitées avec un insecticide (Chlorpyriphos éthyle 25\% + Thirame $25 \%$ ). Sur ces parcelles, deux traitements avec un insecticide foliaire ont été appliqué aux stades montaison et épiaison. L'insecticide utilisé a été la Deltaméthrine $12.5 \mathrm{~g} / \mathrm{l}$ à la dose de $22,5 \mathrm{cl}$ par traitement foliaire ;

T3: Parcelles dont les semences n'ont reçu aucun traitement chimique, cependant deux traitements foliaires ont été appliqués aux stades montaison et début floraison avec la Deltaméthrine $12.5 \mathrm{~g} / \mathrm{l}$ à raison de 22,5cl par stade. Le dispositif expérimental comporte 6 parcelles élémentaires. Chaque parcelle élémentaire est composée de 8 lignes dont deux de bordure. L'écartement entre les lignes est de $0,70 \mathrm{~m}$. La longueur de la parcelle élémentaire est de $10 \mathrm{~m}$ et la largeur de 5,60 m soit une superficie de $56 \mathrm{~m}^{2}$. Une bande de $2 \mathrm{~m}$ sépare les parcelles élémentaires ainsi que les répétitions. La superficie totale de l'essai : $((10 m \times 4)+(2 m \times 3)) \times((5,60 m \times 4)+(2 m \times 3))=$ $1306,4 \mathrm{~m}^{2}$. 


\section{Ouedraogo et al. J. Appl. Biosci. 2015 Inventaire et incidence des insectes inféodes à la culture du fonio (Digitaria exilis Stapf) dans la zone ouest du Burkina Faso.}

Fertilisation et entretien de la culture: Pour la fertilisation, l'engrais NPK a été apporté au semis à la dose de $100 \mathrm{~kg} / \mathrm{ha}$ et en fumure de couverture, la dose de $50 \mathrm{~kg}$ d'Urée par hectare a été appliquée.

Observations entomologiques: Captures des insectes à l'aide des bacs jaunes: Pour la capture des insectes, cinq bacs jaunes ont été remplis au $2 / 3$ de leur volume avec de l'eau additionnée d'une quantité relative de savon liquide comme mouillant. Les bacs ont été dispersés de façon aléatoire dans cinq parcelles élémentaires pour la capture des insectes et cela de l'émergence jusqu'au stade épiaison. Tous les trois jours, les bacs sont déplacés à l'intérieur des parcelles élémentaires. Les insectes ont été recueillis quotidiennement très tôt le matin à l'aide d'un tamis à mailles très fine et d'un pinceau; puis conservés dans de l'alcool à $70^{\circ}$ à l'intérieur des tubes en polyéthylène. Les tubes sont ensuite ramenés et conservés au laboratoire en attendant le tri, le dénombrement et l'identification. Capture des insectes à l'aide du filet fauchoir : La capture des insectes avec le filet fauchoir a été réalisée à l'intérieur de toutes les parcelles élémentaires raison de 10 coups de filet sur les lignes réservées à cet effet. Les captures ont été réalisées une fois par semaine et durant la période allant du stade montaison et au stade épiaison. Les insectes sont recueillis par parcelle élémentaire et placés dans des sachets en plastique étiquetés. Les sachets sont ramenés au laboratoire et conservés au réfrigérateur avant le tri, dénombrement et l'identification des insectes. Identification des insectes : Au laboratoire, les insectes capturés ont été triés et regroupés par ordre à l'aide d'une loupe binoculaire. En fonction des insectes, l'identification des insectes capturés au filet fauchoir et aux bacs jaune a été possible par l'utilisation des manuels d'identification. Les clés d'identification des insectes sont basés sur les observations de Scholtz et Holm, (1986) ; de Launois, (1979) et de Borror et al. (1981). Pour l'identification des espèces de cicadelles appartenant au genre Cicadullina nous avons eu recours à la dissection du genitalia mâle (Webb, 1987). Observations sur les adventices rencontrées dans le champ de fonio: La diversité des adventices dans le champ de fonio a été évaluée à travers un inventaire de toutes les mauvaises herbes rencontrées dans le champ de fonio. L'inventaire des adventices a été réalisé pendant la période des inflorescences de ces adventices. Pour se faire, cinq parcelles élémentaires ont été choisies de manière aléatoire afin d'y recenser la diversité des mauvaises herbes. Le recensement a consisté à un prélèvement de chaque espèce d'adventice rencontrée dans les parcelles élémentaires. La même opération a été répétée dans les autres parcelles élémentaires en ne tenant plus compte des espèces d'adventices déjà rencontrées. Les échantillons d'adventices récoltés sont ramenés au laboratoire afin de procéder à leur identification. La détermination exacte de toutes les espèces végétales rencontrées dans le champa été faite en utilisant le guide sur les adventices tropicales de Merlier et Montegut (1982). Analyses statistiques des données: L'analyse statistique des données a été effectuée à l'aide du logiciel XLSTAT version 6.1.9. Les données ont été soumises à une analyse de variance selon le test de Fisher (intervalle de confiance à 95\%). 


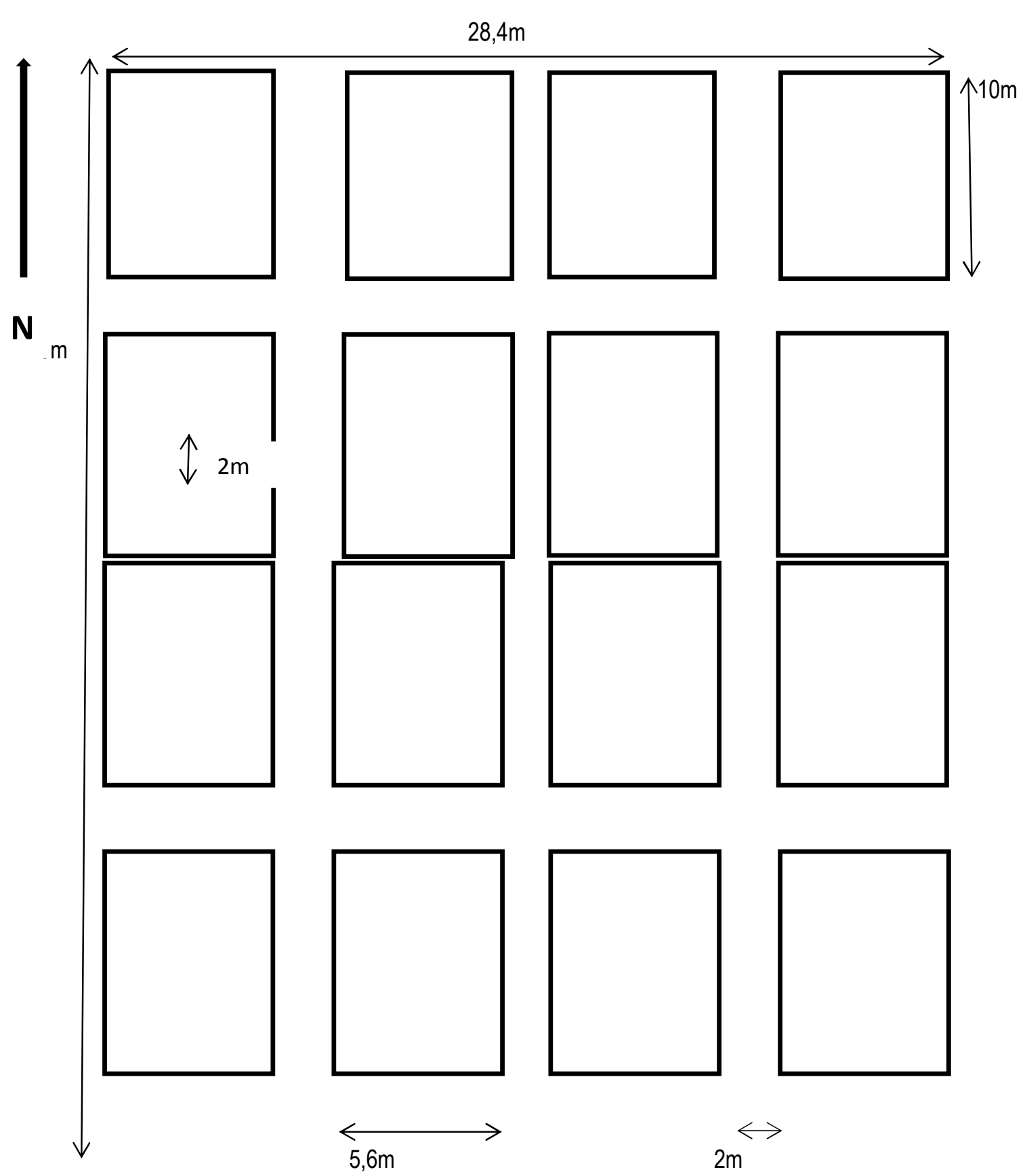

Figure 1 : Dispositif expérimental utilisé

\section{RESULTATS}

Évaluation du taux de levée de la variété Fonio CVF 109 : L'évaluation de la levée des plants de fonio de la variété CVF 109(Figure 1) fait ressortir un taux de levée variant entre 94 et $99 \%$ en fonction des traitements. Le plus faible taux de levée a été observée dans les parcelles dont les semences n'ont reçues aucun traitement avant les semis (T0 et T3), En revanche les plus forts taux de levée (99\%) ont été observés dans les parcelles dont les semences ont reçues un traitement chimique avant les semis (T1 et T2). Cependant, il faut noter que les taux de levée n'ont pas varié significativement suivant les traitements. 


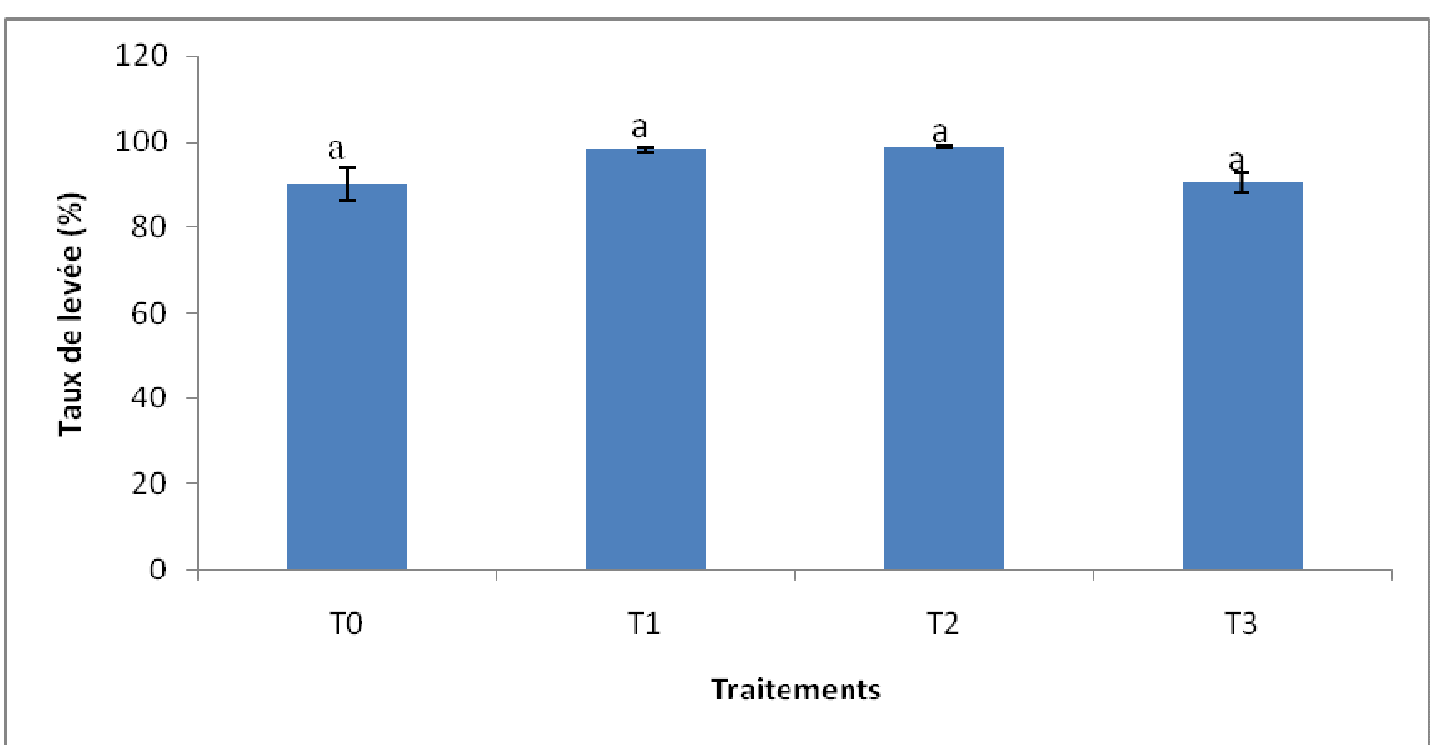

Figure 1 : Évolution du taux de levée de la variété de Fonio CVF 109

Inventaire des insectes dans le champ de fonio: Les insectes capturés dans le champ de fonio ont été dénombrés, regroupés et identifiés suivant l'ordre, la famille et souvent à l'espèce lorsque cela est possible. Les résultats de ces identifications ont présentés au tableau I ci- dessous.

\section{Principaux Ordres et Familles d'insectes rencontrés dans le champ de fonio}

Tableau 1 : Principaux ordres et familles d'insectes capturés sur le fonio

\begin{tabular}{lcc}
\hline Ordre d'insectes & Nombre d'insectes & Nombre de Familles \\
\hline Hymenoptera & 113 & 3 \\
\hline Homoptera & 1448 & 5 \\
\hline Coleoptera & 607 & 15 \\
\hline Diptera & 15 & 3 \\
\hline Heteroptera & 178 & 5 \\
\hline Orthoptera & 245 & 3 \\
\hline Thysanoptera & 163 & 1 \\
\hline Lepidoptera & 27 & 3 \\
\hline Isoptera & $\mathbf{2 2}$ & $\mathbf{1}$ \\
\hline Total & $\mathbf{2 8 1 8}$ & $\mathbf{3 9}$ \\
\hline
\end{tabular}

L'inventaire des insectes capturés dans les bacs jaunes et par le filet fauchoir a fait ressortir que 2818 insectes ont été capturés dans le champ de fonio. Les observations des caractères morphologiques des insectes capturés ont permis de les répartir dans9 ordres (Tableau 1). Le dénombrement des insectes capturés indique que c'est dans l'ordre des Homoptères que les captures ont été les plus importantes avec 1448 insectes suivi de celui des Coléoptères (607 insectes), des Hétéroptères (178 insectes), des Thysanoptères (163 insectes)et des Hyménoptères (113 insectes). Les Lépidoptères, les
Diptères et les Isopteres sont les ordres où on a identifié le moins d'insectes avec respectivement 27 ; 15 et 22 spécimens. Le regroupement des insectes sur la base des principales caractéristiques propres aux familles d'insectes a permis d'identifier 39 familles d'insectes (Tableau 1). II ressort del'analyse du tableau 2 que de toutes de ces familles que 3 familles d'insectes appartiennent à l'ordre des Hyménoptères, 5 familles à celle des Homoptères et 15 familles aux Coléoptères. Quant aux ordres des Diptères, Orthoptères et les Lépidoptères, trois familles d'insectes ont été identifiées dans chacun de ces 


\section{Ouedraogo et al. J. Appl. Biosci. 2015 Inventaire et incidence des insectes inféodes à la culture du fonio (Digitaria exilis Stapf) dans la zone ouest du Burkina Faso.}

ordres. En revanche, une seule famille d'insecte été identifiée dans l'ordre des Thysanoptères et des Isoptères.
Principales espèces d'insectes inventoriés dans le champ de Fonio: Pour l'identification des espèces d'insectes, l'accent a été mis sur les espèces d'insectes ayant un intérêt en agriculture (Tableau 2).

Tableau 2 : Principales espèces d'insectes identifiées sur le fonio variété CVF 109

\begin{tabular}{c|c|c}
\hline Ordres & Familles & Genres et espèces \\
\hline \multirow{4}{*}{ Homoptera } & Delphacidae & Peregrinus sp \\
\cline { 2 - 3 } & Jassidae & Jacobiella facialis (Jacobi) \\
\cline { 2 - 3 } & & Cicadulina mbila \\
\cline { 2 - 3 } & & Cicadulina arachidis \\
\cline { 2 - 3 } & Membracidae & Cicadulina similis \\
\cline { 2 - 3 } & Pentatomidae & - \\
\hline \multirow{2}{*}{ Heteroptera } & & Acrosternum sp \\
& Pirrhocoridae & Aspavia albidomaculata L. \\
\cline { 2 - 3 } & Lygaeidae & Dysdercus sp \\
\hline \multirow{3}{*}{ Lepidoptera } & Noctuidae & Earias insulana ; Spodoptera littoralis \\
\hline & Arctiidae & Amsacta spp \\
\hline Diptera & Diopsidae & Diopsis apicalis \\
\hline & Syrphidae & Syrphus sp \\
\hline Coleoptera & Meloidae & Mylabris sp \\
\hline Hymenoptera & Formicidae & Formicomis sp \\
\hline Thysanoptera & Thripidae & Thrips tabaci \\
\hline Orthoptera & Pyrgomorphidae & Zonocerus variegatus L. \\
\cline { 2 - 3 } & Acrididae & Oedalus senegalensis L. \\
\hline Hymenoptera & Braconidae & Bracon spp. \\
\hline Isoptera & Termitidae & Odontermes sp \\
\hline
\end{tabular}

L'identification des espèces d'insectes capturés a porté sur les insectes appartenant aux ordres des Homoptères, Diptères, Hyménoptères, Lépidoptères, Orthoptères et Thysanoptères (Tableau 2). Dans l'ordre des Lépidoptères, les espèces d'insectes identifiés sont été Earias insulana, Spodoptera littoralis insectes rencontrés sur le coton et Amsacta sp, un insecte nuisible rencontré sur le sésame et le sorgho. Dans l'ordre des Homoptères, les espèces identifiées sont les cicadelles du genre Cicadulina avec les espèces $C$. mbila,C. similis et C. arachidis. Les populations de cicadelles capturées étaient composées majoritairement de femelles. II est à signaler la capture de plusieurs spécimens de Membracidae dont les identifications sont en cours. Au niveau des Hétéroptères, les espèces capturées étaient constituées de populations d'Aspavia albidomaculata, une punaise rencontrée habituellement sur le sorgho. Quant à l'ordre des Orthoptères, les espèces Zonocerus variegatus et Oedaleus senegalensis ont été les espèces les plus rencontrées. Plusieurs autres espèces d'insectes ont été retrouvées dans les autres ordres c'est le cas de Thrips tabacide l'ordre des Thysanoptères et de Diopsis apicali et des syrphes qui relève de l'ordre des Diptère. Un seul genre de termite a été rencontré dans l'ordre des isoptères il s'agit de Ondotermes sp. II faut noter la présence des hyménoptères notamment les fourmis dont la présence a été significative durant la phase de maturité des grains de fonio.

Identification des adventices nuisibles dans le champ de Fonio: L'une des contraintes à une production de qualité du fonio est la présence des mauvaises herbes. 
Tableau 3 : Principales adventices rencontrées dans le champ de fonio

\begin{tabular}{c|c}
\hline Familles & Genres et espèces \\
\hline \multirow{4}{*}{ Poaceae } & Brachiaria Lata (Schumach) Hubb \\
\cline { 2 - 2 } & Digitaria horizontalis Willd \\
\cline { 2 - 2 } & Dactyloctenium aegyptium (L.) Willd \\
\cline { 2 - 2 } & Setaria pallide-fusca (Schumach.) Stapf et Hubb \\
\cline { 2 - 2 } & Paspalum scrobiculatum L. \\
\cline { 2 - 2 } & Rottboellia exaltata L. f \\
\hline Commelinaceae & Eleusine indica (L.) Gaertn \\
\hline Rubiaceae & Commelina benghalensis L. \\
\hline \multirow{2}{*}{ Cyperaceae } & Myllinga squamus villosus (Sw.) DC. \\
\hline Convolvulaceae & Mariscus cylindristachyus Steud. \\
\hline Solanaceae & Cyperus Sp. \\
\hline Malvaceae & Ipomea eriocarpa R. Br \\
\hline Onograceae & Physalis angulata L. \\
\hline Verbanaceae & Hibiscus asper Hook.f \\
\hline & Ludwigia abyssinica A.Rich \\
\hline & Stachytarpheta angustifolia (Mill.) Vahl \\
\hline
\end{tabular}

Les échantillonnages et l'identification des espèces végétales ont été réalisés à la période de floraison des adventices, période qui permet une identification exacte des espèces végétales rencontrées. Les résultats de cet échantillonnage présenté au tableau 3 font ressortir que 17 espèces végétales ont été identifiées dans le champ de fonio. Toutes les espèces végétales identifiées suivant les critères qui leur sont propres ont été réparties dans 9 familles d'adventices. C'est dans la famille des Poacées qu'on a identifié la richesse spécifique la plus importante soit 7 espèces dont Digitaria horizontalis qui se différencie de l'espèce Digitaria exilis (fonio) par sa maturité précoce. Les autres espèces les plus rencontrées ont été Dactyloctenium aegyptium et Brachiaria lata. Les espèces telles que Paspalum scrobiculatum,

\section{DISCUSSION}

L'analyse des résultats sur le taux de levée de la variété de Fonio CVF 109 a révélée traitement des semences assure une levée homogène des grains et une meilleure croissance végétative. II ressort ainsi que la protection des semences de fonio est indispensable comme les autres céréales durant la phase de semis pour lui assurer une bonne levée. Ouattara (2011) rapporte que la protection des semences contre les différents pathogènes terricoles durant la phase de
Rottboellia exaltata et Eleusine indica ont été rencontrés mais en nombre moindre comparativement aux espèces Digitaria horizontalis. En dehors des Poacées, les espèces les plus rencontrées au niveau du champ ont été les Cyperaceae. Dans cette famille, trois espèces ont été identifiées, il s'agitdes espèces Kyllinga squamulata, Mariscus cylindristachyus et Cyperus sp. Dans les autres familles d'adventices rencontrées, nous n'avons identifiés qu'une espèce par famille comme chez les Onograceae avec l'espèce Ludwigia abyssinica. Dans les familles d'adventices telles que les Rubiaceae,Convolvulaceae, Solanaceae, Malvaceae et Verbanaceae nous avons respectivement rencontré les espèces suivantes: Mitracarpus villosus, Ipomea eriocarpa, Physalis angulate, Hibiscus asper et Stachytarpheta angustifolia.

semis est indispensable pour assurer une germination des graines. L'identification des insectes capturés a permis de dénombrer 9 ordres d'insectes qui infestent le fonio. Les insectes les plus nombreux ont été les Homoptères confirmant ainsi les observations de Traoré (1997) qui rapporte que le fonio est une plante attractive pour les homoptères du genre Cicadulina.Lescicadelles du genre Cicadulina qui sont reconnus comme étant les vecteurs du Maize Streak 


\section{Ouedraogo et al. J. Appl. Biosci. 2015 Inventaire et incidence des insectes inféodes à la culture du fonio (Digitaria exilis Stapf) dans la zone ouest du Burkina Faso.}

Virus(Van Rensburg, 1983; Konaté, 1991 ; Konaté et Traoré, 1992). Pour ces auteurs, les champs de fonio constituent un support de ponte et un abri pour les cicadelles qui sont reconnues comme les seuls vecteurs du virus de la Striure du maïs, une maladie virale quis'attaque aux maïs (Traore, 1997).Sur le fonio, ces insectes à travers leurs alimentations transmettent une maladie virale aux plants du fonio qui se caractérise par une décoloration des feuilles et qui empêche les plants malades de faire la photosynthèse. Cette situation peut être non seulement à la base de faibles rendements du fonio mais constituer une source d'infection pour des cultures comme le maïs. Cependant, il faut noter que comme le riz pluvial, les termites dont un seul genre a été identifié peuvent être à la base d'une destruction totale des champs de fonio en cas de sécheresse. La diversité des captures réalisées dans le champ de fonio est importante mais tous les insectes capturés ne sont pas des insectes nuisibles au fonio. En effet, il n'est pas exclu que certaines espèces d'insectes aient été capturés " accidentellement ». C'est le cas de Thrips tabaci, qui est attiré la couleur des bacs utilisés. Nos résultats sont en accord avec les travaux d'Umaru et al. (2010) qui rapportent la présence de plusieurs espèces d'insectes sur une variété defonio durant sa phase végétative. L'importance numérique des insectes capturés traduit l'attirance du fonio pour les insectes. En effet, la croissance des plants de fonio favorisé par un tallage important crée un micro climat qui convient au développement des insectes ce qui explique l'importance des captures. Dans le champ de fonio, le couvert végétal est assuré par les plants de fonio mais également par d'autres espèces végétales. En effet,

\section{CONCLUSION ET APPLICATION DES RESULTATS :}

Les travaux réalisés dans la zone ouest du Burkina Faso ont montré que le fonio durant sa phase de production est infestée par une cohorte d'insectes. L'importance quantitative et qualitative des insectes inféodés au fonio déprécient la qualité de cette céréale. A ce facteur il faut ajouter la diversité des adventices sauvages rencontrés dans le champ de fonio et qui participent également à la dépréciation de la qualité du fonio. L'évolution et la densité des insectes est favorisé

\section{BIBLIOGRAPHIE}

Akobundu I.0.1987. Weed science in the tropics. Principes and practices. Willey, Chichester, UK. 522pages. l'inventaire des espèces végétales réalisées dans le champ de fonio, ont mis en évidence la présence de17 espèces végétales réparties dans plusieurs familles. Deux familles dominent la flore des adventices rencontrée dans le champ de fonio, il s'agit des Poaceae et des Cyperaceae qui appartiennent aux familles d'adventices majeures (Akobundu, 1987).Cette forte présence des adventices constituent une contrainte majeure à une production de qualité du fonio. Les Poaceae ont été les adventices les plus rencontrés et dans cette famille, l'espèce Digitaria horizontalis Willda été la graminée la plus abondante. C'est une espèce apparentée au fonio et qui se développe dans des conditions écologiques similaires sauf qu'il présente un cycle relativement court capable de fleurir 40 jours après émergence (Johnson, 1997). La présence de cette espèce constitue une difficulté importante lors du désherbage manuelle à cause desa forte ressemblance avec les plants de fonio. Cette confusion peut entraîner une baisse de la qualité des semences de fonio mais également être à la base de la prolifération de cette graminée dans les champs de fonio. L'importance et la variabilité des espèces végétales recensées dans le champ de fonio expliquent le nombre et la diversité des insectes identifiés dans le champ de fonio, ces espèces végétales étant les principaux supports nourriciers et de ponte pour les insectes et leurs larves. Ce qui est en accord avec les observations d'Okoth et Dabrowski (1987) qui rapportent que la densité des populations d'insectes augmente avec la disponibilité des plantes hôtes; ce qui explique l'importance et la diversité des insectes capturés sur le fonio.

par le micro climat crée par le tallage du fonio mais également par la présence d'une forte diversité des mauvais herbes. Les résultats obtenus permettent de pouvoir assurer une production de fonio de qualité. En effet, la connaissance et la gestion efficace des insectes nuisibles et des adventices indésirables peut être à la base d'une production de fonio de qualité destiné aussi bien pour la consommation humaine que comme semences.

Borror J.D., De Long D.M., et Triplehorn C.A., 1981. An introduction to the study of insects. Saunders college publishing, fifth edition, 827p. 
Cruz J.F., Dramé D., Diallo T.A. et Son G. 2000. Amélioration des technologies post-récolte du fonio, rapport annuel, projet CFC/IGG (FIGG/02). 79p.

Cruz J.F., Dramé D., Diallo T.A. et Son G. 2005. Amélioration des techniques de transformation du fonio en Afrique de l'ouest. Mécanisation du décorticage et du nettoyage, Maîtrise des Procédés en vue d'améliorer la qualité et la sécurité des aliments. Ouagadougou, 8-11 Novembre 2005. 4 p.

FAOSTAT. 2010. http// faostat.fao.org

Gigou J., Stilmant D., Diallo T A ., Cisse N., Sanogo M. D., Vaksmann M. 2009. Fonio millet response to $\mathrm{N} \mathrm{P}$ and $\mathrm{K}$ fertilizers under varying climatic conditions in West Africa. Experimental Agriculture, 45 :401-15.

MAHRH/DPSAA. 2011. Résultats définitifs de l'enquête permanente agricole. 104 pages.

Konaté G., 1991. Les réservoirs infectieux du MSV au Burkina Faso. Phytoprotection vol.77, pp 132184.

Konaté G. et Traoré O. 1992. Les hôtes réservoirs de la striure du maïs (MSV) en zones soudano sahélienne : identification et distribution spatiotemporelle. Phytoprotection, vol.73, $n^{\circ} 3, p$ 111-117.

Konkobo-Yaméogo C., Chaloub Y., Kergna A., Bricas N., Karimou R. et Ndiaye J.L., 2004. La consommation urbaine d'une céréale traditionnelle en Afrique de l'Ouest : le fonio. Cahier agriculture, Vol. 13, № 1. pp125-128.

Launois M., 1979. Manuel Pratique d'identification des principaux acridiens au sahel. Edition ministère de la coopération et GERDAT (France), 303p.

Merliet H. et Montegut J., 1982. Adventices tropicales, Flore aux stades plantules et adultes de 123 espèces africaines ou pantropicale. ORSTOMGERDAT-ENSH Paris (France), 490p.

Okoth V.A.O. et Dabrowski Z.T., 1987. Comparative biology of some Cicadulina species and population from various climatics zones in Nigeria (Hemiptera: Cicadellidae) Bull. ent. Res. 77, 1-8.

Portères R., 1955. Les céréales mineures du genre Digitaria en Afrique et en Europe. Journal d'Agriculture Tropicale et de Botanique Appliquée. vol. 2 : pp 349-386.

Scholtz H.S. et Holm E., 1986. Insects of Southern Africa. Editions Butterworths publishers, Durban. 502pages.

Traoré N.S. 1997. Étude bioécologique des cicadelles du genre Cicadulina (Homoptera, Cicadellidae), vectrices du virus de la striure du maïs au Burkina Faso. Implications épidémiologiques. Thèse de Doctorat ès Sciences. UFR biosciences, Université de Cocody ; Cote d'Ivoire, 247p.

Umaru A.B., Kolo I.N., Bright E.O. and Labo-Popoola M.E. 2010. Incidence of pest and diseases of Acha at Badeggi in the Southern Guinea savanna zone of Nigeria. Nigeria Agricultural Journal. Vol.41, №1.

Vall E., Andrieu N., Beavogui F, et Sogodogo D, 2011. Les cultures de soudure comme stratégie de lutte contre l'insécurité alimentaire saisonnière en Afrique de l'Ouest : le cas du fonio (Digitaria exilis Stapf). Cah. Agric.vol. 20. p. 294-300.

Vodouhe S.R. Zannou A et Dako E., 2003. Actes du premier atelier sur la diversité génétique $d u$ fonio (Digitaria exilis Stapf) en Afrique de l'Ouest. IPGRI, du 4-6 aout 1998 à Conakry, 76 pages.

Van Rensburg, G D J. 1983. Southern African species of the genus Cicadullina China (Homoptera: Cicadellidae) with descriptions of new species. Entomology Memorandum 57: 1-22.

Webb M. D. 1987. Species recognition in Cicadullina leafhoppers (Hemiptera: Cicadellidae) Vectors of pathogens of gramineae. Bull. of Entomological Research 77 :683-712. 